\title{
New Situation of Global Climate Governance and China's National Program in Response to Climate Change in Post-Paris Agreement
}

\author{
HE Qian \\ International Business School, Shaanxi Normal University \\ Xi'an, Shaanxi 710119 \\ heqian0815@foxmail.com
}

\begin{abstract}
After signing the Paris Agreement, Global Climate Governance is in a New Situation of the world. For China, What's important is how they grab those chances under the New Situation of global climate governance, combination of global climate governance system and domestic low-carbon development strategy plays an important role in climate governance for both China and the world. The paper summarized the new characteristics and trends reflected in the Paris Agreement. In light of China's domestic and international situations, suggestions were proposed that china should advocates a new concept of global climate governance of win-win cooperation, fairness and justice, and common development. Taking cooperation on addressing climate change as an opportunity to promote sustainable development, we try to encourage all countries, especially developing countries, to embark on a climate-friendly low-carbon economic development path and achieve a win-win situation between "development" and "carbon reduction".
\end{abstract}

Keywords-China; Climate change; Paris agreement; Global climate governance

\section{INTRODUCTION}

Climate change has become one of the most serious environmental challenges facing human society. The issue of climate change calls for common and active responses from the international community, as it concerns the well-being of all peoples and the global sustainable development. The global climate governance has been almost thirty years since the signed of the United Nations Framework Convention on Climate Change (UNFCCC) in 1992, while it fails to reach the ideal goal. The global climate governance system is continuing development and improvement from the UNFCCC to the Paris Agreement, which reached in 2015, is an important breakthrough in setting long-term goals, balancing "top-down" and "bottom-up" mechanisms and achieving dynamic assessments. Compared with 90 in the 20th century, the global political economy and GHG emissions has changed remarkably. Meanwhile the internal systems of global climate governance has also constantly evolving. It reflects the transition of the deconstruction of the global climate governance dichotomy, the balance between world power diplomacy and global democracy, the expansion of decision-making horizon and the participation of a wide public. And became a landmark in the global climate governance, laying a better foundation for the international cooperation on climate change practice along with a set of related resolutions [1]. The most important task facing China is how to adjust their existing policies to meet the new situation of global climate governance.

\section{The New Situation Of Global Climate GOVERNANCE}

\section{A. The global climate governance tending to be win-win cooperation around the world}

Recently, the win-win cooperation has already become the focus that international community has paid close attention to, countries around the world began to harness the global climate through peaceful and cooperation means. For example, the Governor of California and Mexico' s environmental officials agreed to create a joint system for carbon trading, which aimed to carbon emission reduction. The United States (US) and China had declared their respective national action target about tackle climate change in the US-China Joint Announcement on Climate Change published in Sep,2015.And further deposited their instruments of ratification to the United Nations Secretary General Ban Ki-moon at 2016 G20 summit in HangZhou. As the two largest economies and biggest carbon emitters globally, the two countries between them account for 40 per cent of greenhouse gas emissions, Chinese-U.S. cooperation set a good example of global climate governance. China-Germany Ecological Garden signed an agreement with Germany Colin industrial technology limited liability companies in June 2016.According to the agreement, Colin industrial will building the research and development, production projects in CCG utilizing waste heat System so as to achieve fume temperature greatly reduced. In July 2016, Maersk Line signed a five-year strategic cooperation agreement with Huawei to achieving commitment to sustainable development. Under the agreement, Maersk Line and Huawei plan to reduce 40 percent Carbon emissions per Container during transportation. Overall, the international community are striving hand in hand to build an international relations with win-win cooperation to achieve global climate governance and sustainable development. 


\section{B. The global climate governance tending to be} institutionalized

Improve the legal framework and advancing the Institutionalization of the global climate governance is the basic approach to global climate governance. In view of the current situation of the rising of global temperature, the Intergovernmental Negotiating Committee for a Framework Convention on Climate Change (INC/FCCC) reached UNFCCC to provide a basic legal framework for global governance on climate change in 1992. The 1997 Kyoto Protocol, the 2012 Doha amendment to the Kyoto Protocol, which made active attempt towards the implementation of the UNFCCC [2]. As specific performances of global climate governance institutionalize, these provide "Soft Law" and "Hard Law" to normalize the global climate governance process. In 2015, the Paris agreement approved at the Paris climate change conference, suggests international should enhance cooperation about tackling climate change to achieve the goals of zero net GHG emissions globally. A part of countries and international organizations institutionalized their global climate governance process additionally. For instance, The European Commission has proposed the Long-term goals that reduce 60 percent $\mathrm{GHG}$ emission at 2050 compared with 2010 in Feb, 1943.

\section{The model of global climate governance transfer from top- down to bottom-up}

The 1997 Kyoto Protocol distribute the emission targets in a legal way, that was the beginning of the top-down model of global climate governance. This model with strict compliance mechanism has strong binding force of law, while it is difficulty to agree consensus on action. Canada withdraw from Kyoto is an example. The framework of global climate governance consisted of UNFCCC and the Kyoto resulted in firewall between developed and developing countries [3]. Therefore, the model of global climate governance has transferred to bottom-up. The Paris agreement building a new global climate governance system based on Intended Nationally Determined Contribution (INDCs). So far there are 188 Parties handed in their INDCs, almost 100 percent of global emissions. China put forward to achieve the carbon emissions peak before 2030, and CO2 per unit of GDP decrease 60 65 percent in INDCs, Japan has expressed that domestic carbon emissions decrease 26 percent at 2030 compared with 2013,for example. The bottom-up model of global climate governance is the significant turning point of global climate governance model, nations submit INDCs according to their ability and national conditions, and it can be breakdown of the firewall between developed and developing countries.

\section{The power of climate governance of developing countries has improved}

On the subject of climate change, it's a global problem. Both of developed and developing countries should actively participate in climate governance process. With the rapid development of economics and consistent growth in carbon emissions, developing countries has powerful structural power gradually. The "basic" ( Brazil, South Africa, India and China) 4 countries, an example, their carbon emissions and energy demand increasing, at the same time, structural power and say increases ceaselessly. For instance, at the Doha climate talks, the BASIC group made full use of above powers to guarantee the second commitment period of Kyoto from the legal aspects and promotes the establishment of the principle of Durban negotiations. Besides that, in the field of rainforest protection, Indonesian and Brazil successfully introduce the system to emission reduction of deforestation and forest degradation by using their structural power[4].In Apr,2015,Mexico has submit their education schemes to The United Nations, and became first volunteered to GHG emissions reduction. Other developing countries, especially Alliance of small island states and poor developing countries, as the biggest victims of climate change, has more say about global climate governance.

\section{ChinA'S NATIONAl PROGRAM Under THE NeW Situation Of Global Climate GovernanCE}

In the report of 19th CPC National Congress, Xi Jinping put forward the goal of building "beautiful China", and points out the principal contradiction facing Chinese society has evolved.

China has played an important role in the signing, ratification, entry into force and promotion of the Paris agreement in international climate change negotiations, so to speak, which fully showed it is a responsible power while also showed their resolution of building a community of human destiny. With the gradual evolution of the political structure of Climate Chang, the expectations of international community for China and the Chinese people for the government will continually growing. During the process, low-carbon development will become an important approach to China to participate in the Global Climate Governance and settling the problem of environmental issues.

From the international level, the developing countries, with the BASIC group as the representative, achieving substantial growth in economic aggregates and total GHG emissions, notably China as the biggest GHG emitter and the world's second-largest economy. China facing the huge pressure of foreign country with the increasing demand for mandatory emission reduction. From the domestic level, after reformation and opening, with the acceleration industrialization and urbanization of China, a series of environmental problems, such as haze, ecological ruining and environmental pollution have been arose to compel low-carbon development in home. The low-carbon development strategy of China is a realistic choice pushed by the pattern of global climate governance and domestic factors actually. Not only should China government consider the domestic practical conditions but also take into account the background of global climate governance and 
development trends of Telecom technologies, finally realize the full integration of climate diplomatic strategy with the lowcarbon development strategy of China.

\section{A. The internationally oriented strategies}

Now climate diplomacy has become one of the representative characteristics in the way China participated in global climate governance, China must through the implementation of "low carbon economy" development strategy to effectively promote the process of global climate governance, including international especially to most developing countries and domestic low carbon development. Globally speaking, firstly, further participated in global climate governance with a more enthusiastic posture, make energetic efforts for the negotiating process of global climate governance and international co-operation to constructs more stable living environment of the global low carbon development. Second is tring to coordinate the stand of the developing countries and protect the legitimate rights and interests of developing countries in order to strive for a favorable condition for the developing countries [5]. And third is further consolidating the currently international exchanges and co-operation, prompting the developing countries to achieve low-carbon development with multilayer more trenches international exchange and cooperation, especially by the South-South Cooperation Fund for climate change, and conduct capacity building such as lowcarbon construction demonstration area, launch project of mitigation and adaptation, further strengthens the capacities of use the green climate fund and improve low-carbon development level in developing countries. Fourth, China should positively introduce its achievement of low-carbon development on occasions of international bilateral and multilateral climate diplomatic, increase the theory and practices of the international influence of China's Construction of Ecological Civilization, further shows the determination and will of China's Construction of Ecological Civilization, to enable Chinese as significant player, contributing member, leader in the global Construction of Ecological Civilization [6].

\section{B. The domestic-oriented strategies}

Domestically, a lot of ground of economic and social development has been covered in China's low-carbon development strategy, such as production methods, people's lifestyle and values. Specifically:

Firstly, low carbonization in the field of production. Building a low-carbon industrial system and promoting the transformation and upgrading of industrial structure by the support of some external factor such as low carbon technologies, policies, ideas. And its core is improve productivity of low carbon production to reduce emission during the production process. In the industrial field, lowcarbon technically reform and upgrade is necessary. Value the design of a low-carbon developmental path of new industrial capacity. And adjust the international standing of international industry chain of China' $\mathrm{s}$ industry. We should energetically develop cross-industrial symbiosis to achieve collaborative emission reduction and implement leap-forward low-carbon development of industrial through informationization. To establish the perfect economic to green, low-carbon and circular economic development system. In the agricultural sector, clarifying the key point of GHG emission in the agricultural production process starting from producer's behavior, changing the mode of agricultural production, achieving low-carbon agricultural development through the implement of rural revitalization strategy and supply-side reform of agricultural. And attaches great importance to combine the comprehensive improvement of the rural human settlements to actively exploring the developmental path of low-carbon agricultural. Finally, in the service sector, promoting the transformation of service industry, full use of the advantage of new technologies and new business model such as sharing economy, fully stimulating the service sector's GHG emission reduction potential by accelerating the development of the modern service sector.

Second, low carbonization in the field of life and consumption. With the rapid development of industrialization and urbanization in China, On the one hand, the habit of society consumption changes because of a large rural population is moving into the cities becoming citizens and further brings pollution and increase consumption of resource. On the other hand, greater purchasing power with more disposable incomes will resulted the emission increase in the field of life and consumption simultaneously. A number of important strategic measures will be also implemented to speed up the low carbonization in the field of life and consumption. The first is to encourage individuals or families to pursuit of low carbon lifestyle and consumption pattern in the daily life. Such as encourage the life rubbish classification, minimize the production of disposable products and low carbon transportation of city habitant. Second is advocate individuals or families pay more attention to low-carbon products, and giving consumers more incentives to make purchasing decisions towards energy efficient and low carbon emission products. And third is innovate on the systems and mechanisms, impel people' s enthusiasm of low carbon living system, and further achieve the low carbonization in the field of life and consumption

Thirdly, low carbonization in the field of ideology and value. Besides the low carbonization in the field of production and the field of life and consumption, the low carbonization in the field of ideology and value is also important to realize lowcarbon economy development. In the process of strategies, decision making should pay attention to the following points. The first is realize deep Integration of low-carbon values, ecological civilization construction and green development strategy. Promoting the low-carbon values grounded in the whole process of the implement of above strategies and making low-carbon values becoming the mainstream value of a society and further will be an important content in core socialist values. Second is Integrate the low-carbon values with the original value system, combined the low-carbon values with Chinese traditional virtues as diligence and frugality. Accelerating the improvement of society' low carbon awareness embodied low carbon perception. And third is pay much attention on environmental education. Promoting the environmental education legislation in China nationally as soon as possible, integrate low-carbon concepts into the teaching system of preschool, primary and secondary schools, colleges 
and universities and social vocational training to achieve full coverage of low-carbon education.

\section{CONCLUSION}

After the Paris Conference, the major of states parties to the Paris agreement have been in relentless efforts to implementate the Paris agreement, controlling carbon has become the global mutual recognition. As a responsible big country, China should be based on the current global climate governance system and timely adjust. And making corresponding strategies in different fields and stages to further optimize the industrial structure, contribute the low-carbon construction and energy environmental policy innovation to the sustainable healthy development of the world economy and the improvement of human living environment in the future.

\section{REFERENCES}

[1] S Maljean-dubiois. "The Paris Agreement: A New Step in the Gradual Evolution of Differential Treatment in the Climate Regime?" Review of European Comparative \& International Environmental Law, vol 25, pp.151-160, Feb 2016.

[2] K Bäckstrand, JW KUYPER, B Linnér, et al. "Non-state actors in global climate governance: from Copenhagen to Paris and beyond," Environmental Politics, vol 26, pp. 561-579, 2017.

[3] Stone C D. "Common but Differentiated Responsibilities in International Law," American Journal of International Law, vol.98, pp. 276-301, 2004

[4] Stavins R. "The Economics of Climate Change," University of Chicago Press, pp. 1-37, 2011.

[5] The Lancet. The Lancet Countdown on Health and Climate Change: From 25 Years of Inaction to a Global Transformation for Public Health [R]. 2017.

[6] CAT. Improvement in Warming Outlook as India and China Move Ahead, but Paris Agreement Gap still Looms Large [R]. 2017. 